\title{
Numerical Simulation of the Effects of Grassland Degradation on the Surface Climate in Overgrazing Area of Northwest China
}

\author{
Yanfei Li, ${ }^{1}$ Zhaohua Li, ${ }^{1}$ Zhihui Li, ${ }^{2,3,4}$ Xiaoli Geng, ${ }^{1}$ and Xiangzheng Deng ${ }^{3,4}$ \\ ${ }^{1}$ Faculty of Resources and Environmental Science, Hubei University, Wuhan, Hubei 430062, China \\ ${ }^{2}$ University of Chinese Academy of Sciences, Beijing 100049, China \\ ${ }^{3}$ Institute of Geographic Science and Natural Resources Research, Chinese Academy of Sciences, Beijing 100101, China \\ ${ }^{4}$ Center for Chinese Agricultural Policy, Chinese Academy of Sciences, Beijing 100101, China
}

Correspondence should be addressed to Xiangzheng Deng; dengxz.ccap@gmail.com

Received 17 July 2013; Accepted 26 September 2013

Academic Editor: Burak Güneralp

Copyright (C) 2013 Yanfei Li et al. This is an open access article distributed under the Creative Commons Attribution License, which permits unrestricted use, distribution, and reproduction in any medium, provided the original work is properly cited.

\begin{abstract}
The climatic effects of LUCC have been a focus of current researches on global climate change. The objective of this study is to investigate climatic effects of grassland degradation in Northwest China. Based on the stimulation of the conversion from grassland to other land use types during the next 30 years, the potential effects of grassland degradation on regional climate in the overgrazing area of Northwest China from 2010 to 2040 have been explored with Weather Research and Forecasting model (WRF). The analysis results show that grassland will mainly convert into barren land, croplands, and urban land, which accounts for $42 \%$, $48 \%$, and $10 \%$ of the total converted grassland area, respectively. The simulation results indicate that the WRF model is appropriate for the simulation of the impact of grassland degradation on climate change. The grassland degradation during the next 30 years will result in the decrease of latent heat flux, which will further lead to the increase of temperature in summer, with an increment of $0.4-1.2^{\circ} \mathrm{C}$, and the decrease of temperature in winter, with a decrement of $0.2^{\circ} \mathrm{C}$. In addition, grassland degradation will cause the decrease of precipitation in both summer and winter, with a decrement of $4-20 \mathrm{~mm}$.
\end{abstract}

\section{Introduction}

The influence of human activities on the climate system has become the focus of the academic community at home and abroad in the context of global warming since the 20th century [1]. The fourth assessment report of Intergovernmental Panel on Climate Change (IPCC AR4) indicated that the human activities are an important influencing factor of climate change, accounting for $90 \%$ of global warming $[2$, 3]. Some previous researches have showed that the humaninduced land use/land cover change (LUCC) was one of the major factors, which influence the regional climate [4]. The LUCC influences the climate change mainly through changing the underlying surface properties such as the surface reflectivity, roughness, soil moisture, leaf area, and vegetation coverage $[5,6]$. The effects of LUCC on the biogeophysical processes vary from region to region, which are closely related with the land-atmosphere interaction, regional surface climate, environmental background and vegetation, and so forth, $[7,8]$. Therefore, it is of great significance to study the effects of LUCC on regional climate for adapting to climate change.

Grassland as one of the most widespread land use type covers about $40 \%$ of the total land area of China $[9,10]$. The grasslands provide various ecosystem services such as the provision of the forage, milk, and meat. Besides, the grasslands also provide some important ecosystem services that regulate the regional climate, for example, the mitigation of greenhouse gas (GHG) emissions through soil organic carbon $(\mathrm{C})$ and nitrogen $(\mathrm{N})$ sequestration $[11,12]$. Therefore, the grassland change would be the import factor influencing the climate change. The overgrazing areas in Northwest China are the most significant hinterlands. The grassland degradation and desertification in overgrazing area of Northwest China has greatly intensified due to the irrational exploitation of the natural resources, rapid population growth, and the expansion of road network in recent years $[13,14]$. The mean rate of grassland degradation has accelerated overall in the 


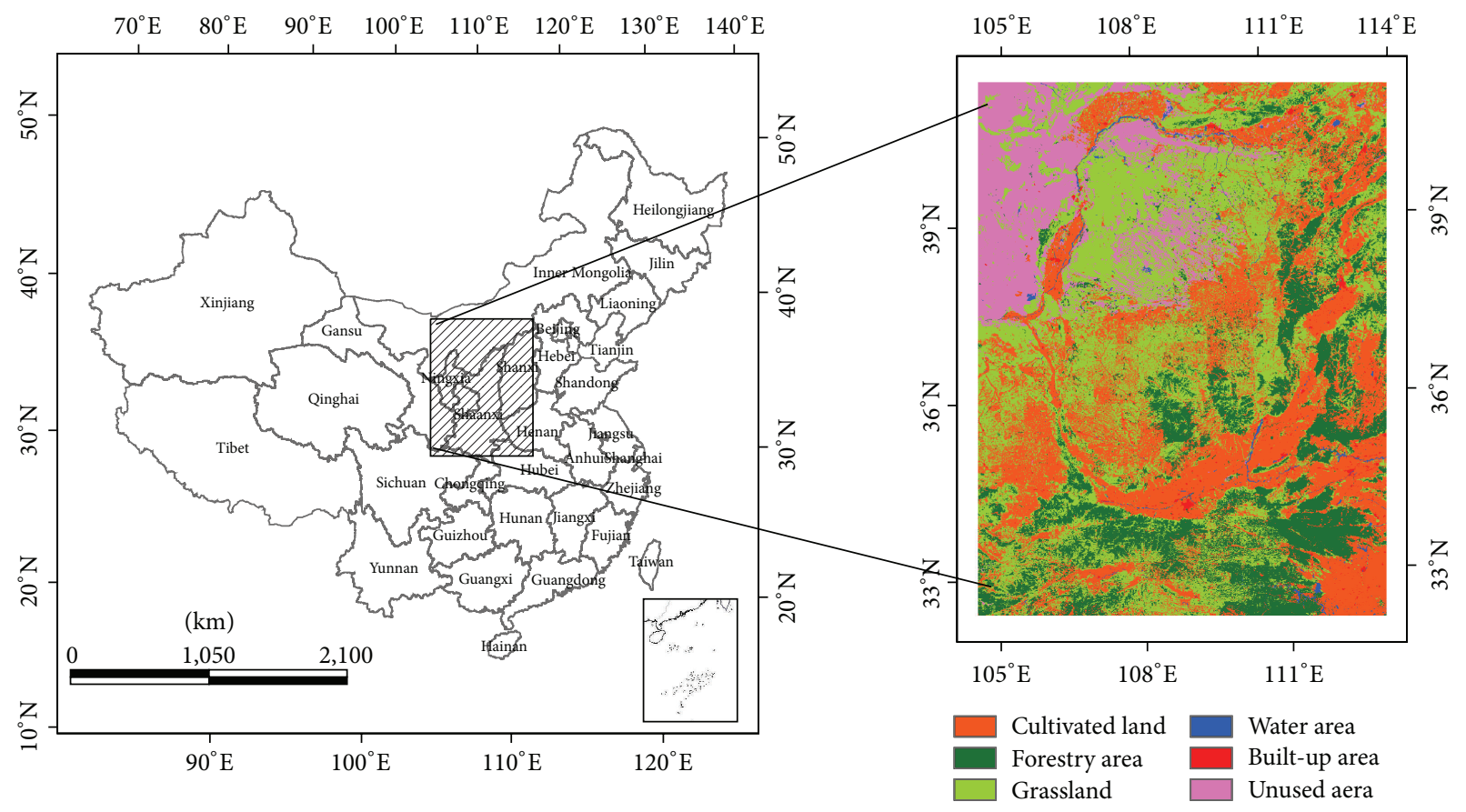

FIgURE 1: Location of the study area and the distribution of land use type in the overgrazing areas of Northwest China.

past 50 years and only decelerated in recent years. Moreover, the grassland degradation has led to the decline of grassland productivity and increased the frequency of extreme climate events such as droughts and fierce freeze-up, which have seriously influenced the sustainable development of animal husbandry [14]. Therefore, it is of great importance to study the influence of grassland degradation on the climate in the overgrazing area of Northwest China.

There have been many researches focusing on the impacts of the grassland degradation in overgrazing areas in Northwest China on climate change. Most of those researches detected the interaction between the grassland degradation and the climate change by the selection of regional climate model (RCMs) or global climate models (GCMs) and experiment designs [15]. Xue and Fu et al. identified that grassland degradation over the Mongolian and the Inner Mongolian grassland could bring significant influence on surface climate $[16,17]$. Zhang et al., found that the grassland degradation could lead to the decrease of precipitation and the increase of surface temperature in Northwest China [18]. Liu et al. found that the grassland desertification can lead to grand temperature increase in the daytime and decrease at night, and the sensitive heat flux increase and the latent heat flux decrease in the Source Regions of Three Rivers [19]. All of these previous researches with GCMs and RCMs have contributed to the comprehensive understanding of the impacts of grassland change on the climate change at the regional and global scales. However, because of the coarse resolution, there are some bias and uncertainties in the simulation of the regional climate change with GCMs [20-24]. The weather Research and Forecasting (WRF) model represents the recent advances of RCMs and is specifically designed for high resolution applications and provides an ideal tool for assessing the value of high resolution regional climate modeling, and some researchers have identified the WRF model to be superior to other RCMs such as RegCM2, RegCM3, RAMS, RIEMS, RegCM-NCC, and IPCR-RegCM [1, 25, 26].

Some studies with the WRF model have shown that grassland degradation in overgrazing areas of Northwest China has obvious effect on the regional climate $[19,24]$. However, those previous researches about the effects of grassland degradation on the climate change have generally focused on the effects of land change during the historical period with the numerical simulation models, while there were few researches on the impacts of predicted future land use change on the climate. Therefore, this study aims to estimate the potential impacts of grassland degradation on climate change in overgrazing area of Northwest China from 2010 to 2040 with the WRF model.

\section{Data and Methodology}

2.1. Study Area. The overgrazing area of Northwest China is located in $104^{\circ} 04^{\prime} \sim 114^{\circ} 02^{\prime} \mathrm{E}, 32^{\circ} 40^{\prime} \sim 41^{\circ} 20^{\prime} \mathrm{N}$ with a total land area of $811856 \mathrm{~km}^{2}$ covering five provinces which include Ningxia Province, the south east part of Gansu Province, Shaanxi Province, the west part of Shanxi Province, and the middle and south west part of Inner Mongolia Autonomous Region (Figure 1). It is one of the largest grazing areas of China, which is the major production base of the animal husbandry industry in China. 
This region stretches across the eastern monsoon region and northwest arid region and is close to the QinghaiTibet alpine region, approximately located in the transition zone of the three major natural zones of China. It is the continental semiarid climate in this region, with an annual average temperature of $5-10^{\circ} \mathrm{C}$ and the annual precipitation of $200-800 \mathrm{~mm}$. There is very limited water resource, the spatiotemporal distribution of which is very imbalanced, and there are frequently meteorological disasters.

The grassland and cultivated land are the dominant land use types in this region, accounting for 36.19\% and 29\% of the total area, respectively. The irrational utilization of grassland resources is very common due to overgrazing and overreclamation under the influence of pursuit of economic benefit since the 1980s. It has led to the continual degradation of the grassland. The proportion of grassland accounting for the total area of Northwest China has decreased from about $36 \%$ in 1995 to $31 \%$ in 2008 , and most of grassland degraded into barren land and croplands. The intensive grassland degradation has resulted in more and more acute contradiction between the human and nature, economic development and eco-environmental conservation in region. Therefore, the exploration of the degree and mechanism of grassland degradation's influence on regional climate and environment is of great significance to the policy making of the regional sustainable land use and management.

2.2. Data Resource. In this study, the $1 \mathrm{~km}$ resolution land cover data of United States Geological Survey (USGS) classification in 2010 were extracted from the MODIS dataset. The land conversion data with $1 \mathrm{~km}$ resolution used to forecast the information of land use change (land conversion among different land cover types) during 2010-2040 were simulated based on Representative Concentration Pathways 6.0 (RCP6.0) using the Asia-Pacific Integrated Model (AIM) developed by the National Institute of Environmental Studies (NIES) in Japan. According to the requirement of the WRF model, it is necessary to convert the $1 \mathrm{~km}$ resolution land cover data of United States Geological Survey (USGS) classification in 2010 into the $30 \mathrm{~km}$ resolution data.

The meteorological data used in this study, including the near-surface temperature and precipitation, were all from 84 meteorological stations in Ningxia Province, Inner Mongolia Autonomous Region, Gansu Province, Shanxi Province, and Shaanxi Province. In order to analyze the simulation accuracy of the WRF model, the original data of annual average temperature, monthly average temperature and annual precipitation in year 2010 were interpolated into $1 \mathrm{~km}$ resolution grid data with the Kriging interpolation method and then compared with the simulation results.

The atmospheric forcing data such as air temperature, specific humidity, sea level pressure, eastward wind, northward wind, and geopotential height from 2010 to 2040 used in this study were from a state-of-the-art multimodel dataset produced by the fifth phase of the Coupled Model Intercomparison Project (CMIP5) [27].
TABLE 1: Parameterization scheme of physical processes in the WRF model.

\begin{tabular}{lc}
\hline Classification of schemes & Scheme option \\
\hline Physics parameterization scheme & WSM3-class simple ice \\
Cumulus parameterization scheme & Grell-Devenyi ensemble \\
Boundary layer process scheme & YSU \\
Radiation scheme & CAM 3 radiation \\
Land surface process scheme & Noah land surface model \\
\hline
\end{tabular}

2.3. Description of the WRF Model. The WRF model is a next-generation forecast model developed by the scientific research center, atmospheric administration (NOAA), research institutions and universities in the United States. Two motive power cores were included in the WRF model, that is, ARW (Advanced Research WRF) developed by NCAR and used in scientific research and nonhydrostatic Mesoscale Model (MMM) developed by NCEP and widely used in the business system. This study has mainly used the ARW model [28].

The parameterization scheme of physical processes in the WRF model in this study is as follows (Table 1). It mainly includes the WSM3-Class simple ice physical scheme, ensemble cumulus convection schemes of Grell-Devenyi ensemble, YSU, CAM3 radiation schemes, and consolidated NOAH land surface parameterization scheme [29, 30].

2.4. Test Design. In this study, two numerical simulation tests, including the control test and sensitivity test, were designed and performed with the same horizontal resolution and parameterization scheme in order to analyze the effects of grassland degradation on the regional climate more accurately, unlike other previous experiment studies in which the entire grassland was replaced by other land covers. The control test as a reference case used the land cover data of 2010, while the sensitivity test used the land cover data from 2010 to 2040 , in which part of grassland converted into bare land, croplands, and urban land. The climate forcing data in both the control test and sensitivity test were all from 2010 to 2040 . The center of the simulated area is located at $37^{\circ} 53^{\prime} \mathrm{N}, 109^{\circ} 1^{\prime} \mathrm{E}$ with two standard parallels of $39^{\circ} \mathrm{N}$ and $35^{\circ} \mathrm{N}$, including 27 grid points in the east-west direction and 48 grid points in the north-south direction. The simulation period is 30 years from January 1st, 2010, to December 31th, 2040.

\section{Result}

3.1. Forecast of Future Grassland Degradation in Overgrazing Areas of Northwest China during 2010-2040. The grassland in the study mainly concentrates in the south and middle part of Inner Mongolia and Ningxia Province, the northeast of Gansu Province, and south part of Shaanxi Province, accounting for about 35\% of the total area of overgrazing areas in Northwest China. This study stimulates the grassland change of overgrazing areas in Northwest China from 2010 to 2040. The stimulation result indicated that with the 


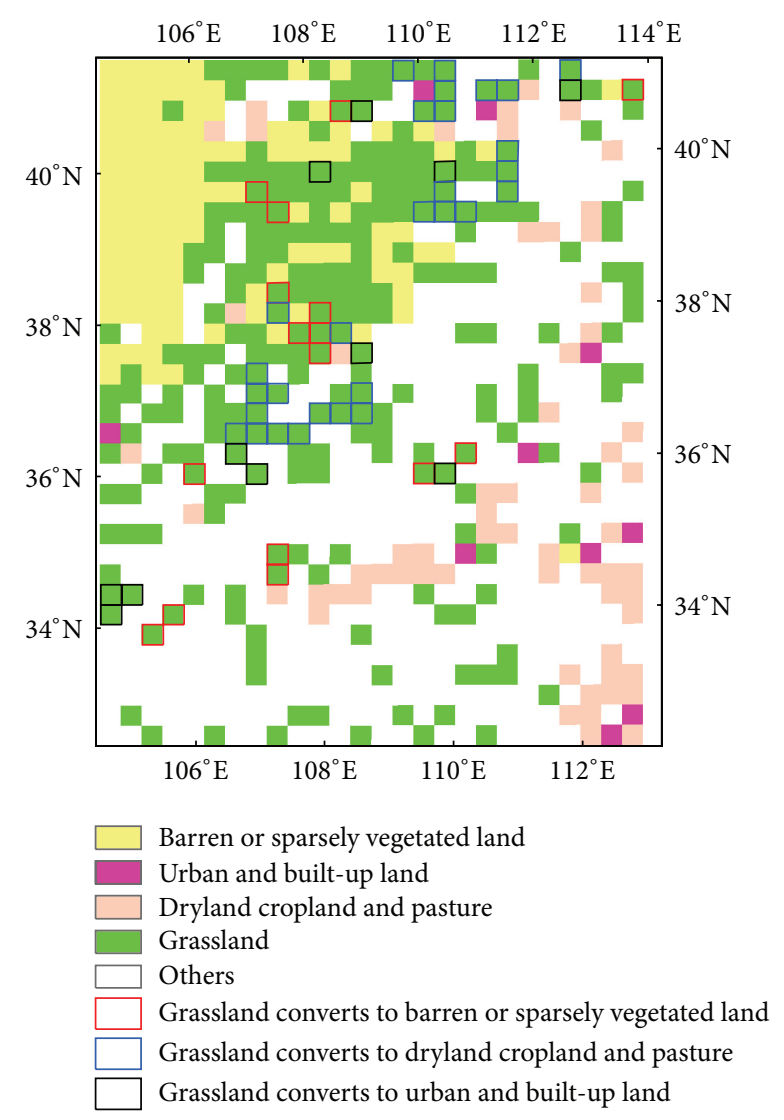

FIgURE 2: Conversion from grassland to other land use types between 2010 and 2040 of the overgrazing areas in Northwest China.

increasing population and unreasonable use of the grassland, the grassland degradation is still severe, in the future 30 years; the conclusion will be coherent with that of previous study [31]. There will be mainly the conversion between grassland and croplands, bare land, and urban land.

This study also statistically analyzed the number of grid cells converting from grassland into other land types between 2010 and 2040. The result indicates that there will be 55 grids converting from grassland into other land types from 2010 to 2040 in the study area (Figure 2). About $48 \%$ of the converted grassland will convert into croplands, which mainly distributed in the southeast part of Inner Mongolia Autonomous Region, northwest part of Shaanxi Province, and northeast part of Gansu Province. The obvious conversion from grassland into barren land will mainly occur in south and central part of Inner Mongolia and Shanxi Province, south part of Ningxia Province, and southeast part of Gansu Province, accounting for $42 \%$ of the total number of converted grids. There will be 9 grids converting from grassland into urban land, accounting for about $10 \%$ of the total number of converted grids. In summary, the grassland in overgrazing areas in Northwest China will mainly convert into barren land and croplands.

3.2. Result of the Control Test. It is necessary to investigate whether the WRF model can well simulate the climate change in the overgrazing areas of Northwest China since the performance of the WRF model in different regions may vary greatly. In this study, the simulation ability of WRF model was tested through comparing the stimulated temperature and precipitation with the observation data.

The result indicates that the WRF model can simulate the temporal change of temperature very well (Figures 3(a) and 4(a)). According to the monthly temperature change in the entire study area, the simulated temperature is roughly consistent with the observed value in the spring and winter, and the difference between them ranges from $0^{\circ} \mathrm{C}$ to $0.5^{\circ} \mathrm{C}$ (Figure 3(a)). However, the temperature is obviously lower than the observed value in both the summer and autumn, with the difference between them ranging from $0.5^{\circ} \mathrm{C}$ to $2.5^{\circ} \mathrm{C}$. As can be seen from Figure 4(a), the stimulated annual average temperature is lower than the observed value, and the difference between them ranges from $0.2^{\circ} \mathrm{C}$ to $1.4^{\circ} \mathrm{C}$, indicating that there is only slight difference between the stimulated and observed annual average temperature.

As can be seen from Figure 3(b), the stimulated precipitation in the spring and autumn of 2010 is lower than the observed value, and the difference between them ranges from $5 \mathrm{~mm}$ to $40 \mathrm{~mm}$ in most months except June. Figure 4(b) reveals that the annual precipitation of 2010 in overgrazing areas in Northwest China, especially the southeast part of Gansu Province and northwest of Shaanxi Province, is lower than the observed value, and the difference between them generally ranges from $5 \mathrm{~mm}$ to $30 \mathrm{~mm}$. In summary, the difference between the simulated and observed monthly and annual change of precipitation is not very obvious. Therefore, the WRF model can well simulate the monthly and annual change of precipitation very well.

3.3. Effects of Grassland Degradation on Latent Heat Flux. The land cover change can influence the energy balance of the earth-gas system through changing the underlying surface parameters such as the land surface albedo, roughness, and soil water content [26]. Latent heat flux is the indispensable element of energy exchange between land surface and atmosphere [32]. The grassland degradation could decrease the roughness, which would lead to the decrease of latent heat exchange in the earth-gas system. As can be seen from Figure 5, the grassland degradation would result in the obvious decrease of the average monthly latent heat flux from March to July, and the maximum decrement reaches about $10 \mathrm{~W} / \mathrm{m}^{2}$.

\subsection{Effects of Grassland Degradation on the Land Surface Tem-} perature. The land use/cover change influences the regional surface temperature through altering the land roughness, and soil hydrological and thermal features, which lead to further change of the land surface energy balance, long wave radiation, fluxes of momentum, sensible heat and latent heat, and so forth [33]. While the impacts of grassland degradation on the temperature in overgrazing areas of Northwest China can be analyzed through calculating the difference in the annual average near-surface temperature (air temperatures at two meters above the ground) between the results of the control 


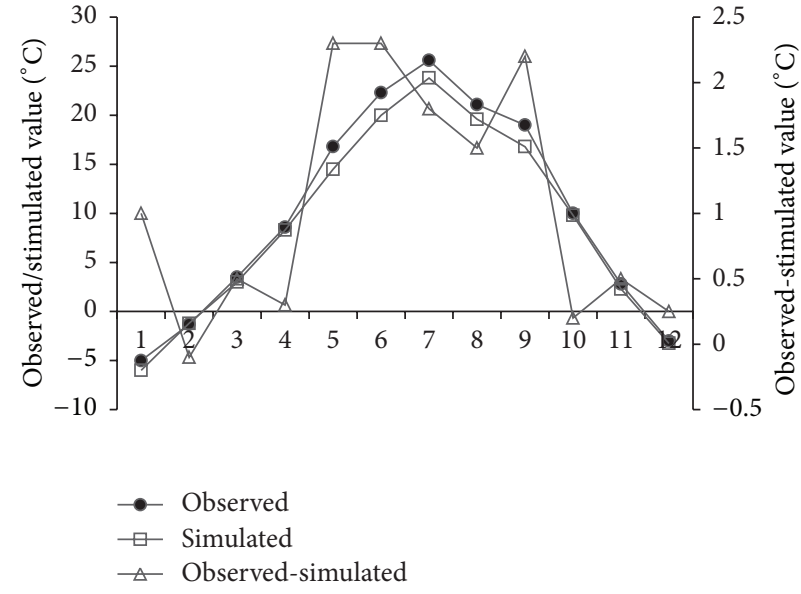

(a)

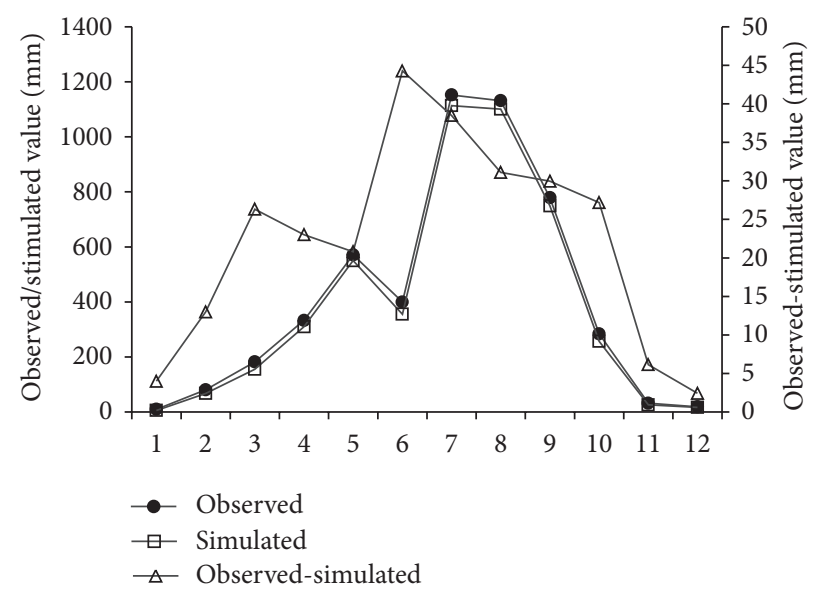

(b)

FIGURE 3: Difference between the observed and simulated monthly temperature ((a), unit: $\left.{ }^{\circ} \mathrm{C}\right)$ and precipitation ((b), unit: mm) of 2010 in the overgrazing areas of Northwest China.

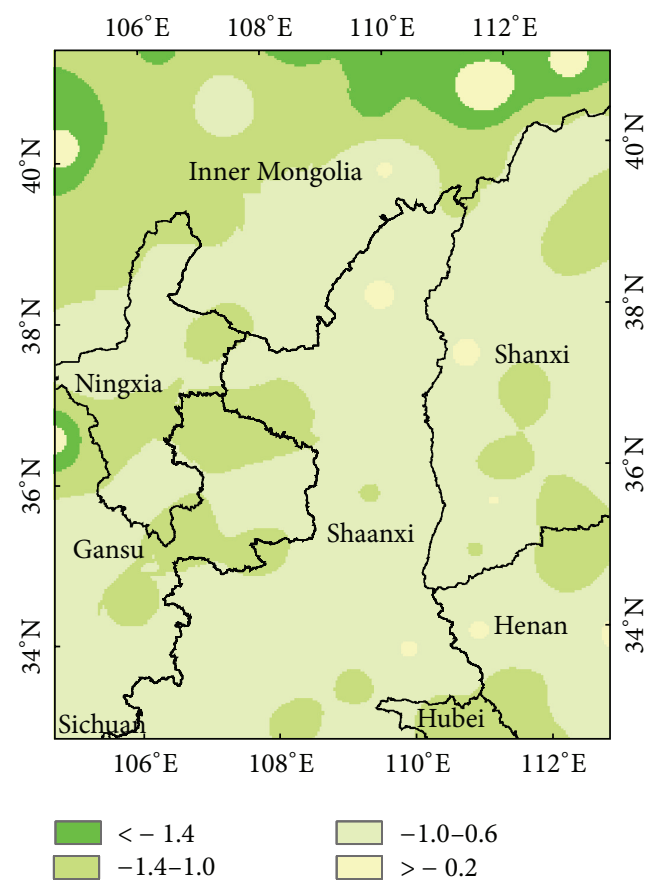

(a)

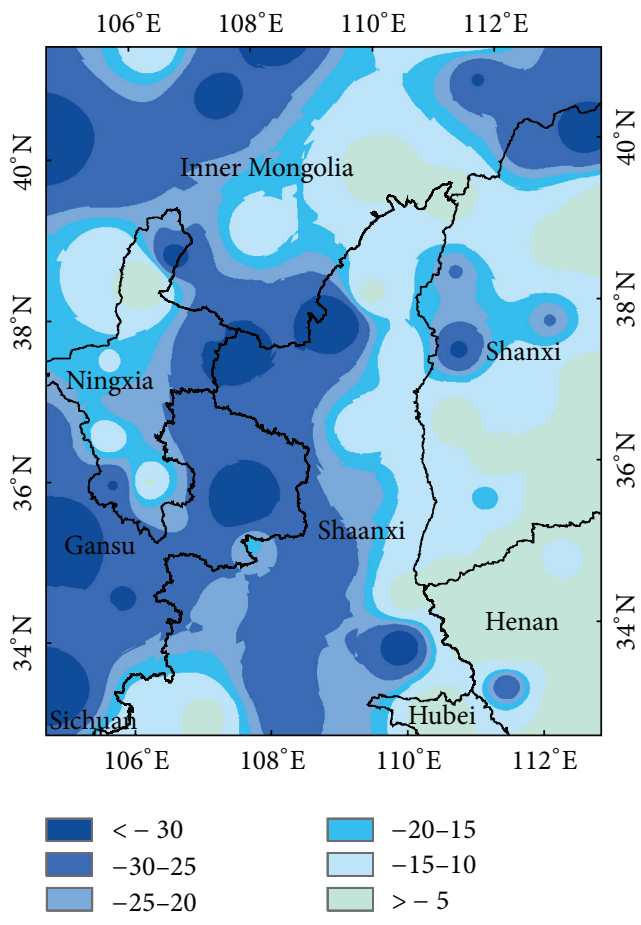

(b)

FIGURE 4: Difference between the simulated and observed annual average temperature ((a), unit: $\left.{ }^{\circ} \mathrm{C}\right)$ and annual precipitation $((\mathrm{b})$, unit: $\mathrm{mm})$ in the overgrazing areas of Northwest China in 2010.

test and sensitivity test on the basis of the simulation in the control test and sensitivity test, the simulation result indicates that there will be different climate effects of the grassland degradation in different areas and seasons from 2010 to 2040 in the overgrazing areas of Northwest China (Figure 6). Besides, the results of the two tests showed that the grassland degradation would increase the land surface albedo, which could lead to the decrease of near-surface temperature in the winter in the middle part of Inner Mongolia Autonomous Region, southwest of Ningxia Province, and northwest of Shanxi Province due to the conversion from grassland to barren land and urban land with the decrement reaching $0.2^{\circ} \mathrm{C}$ (Figure 6(a)). Although the near-surface temperature of the winter increased in the middle part of Shaanxi Province and north part of Shanxi Province due to the decrease of land surface albedo caused by conversion from grassland to 


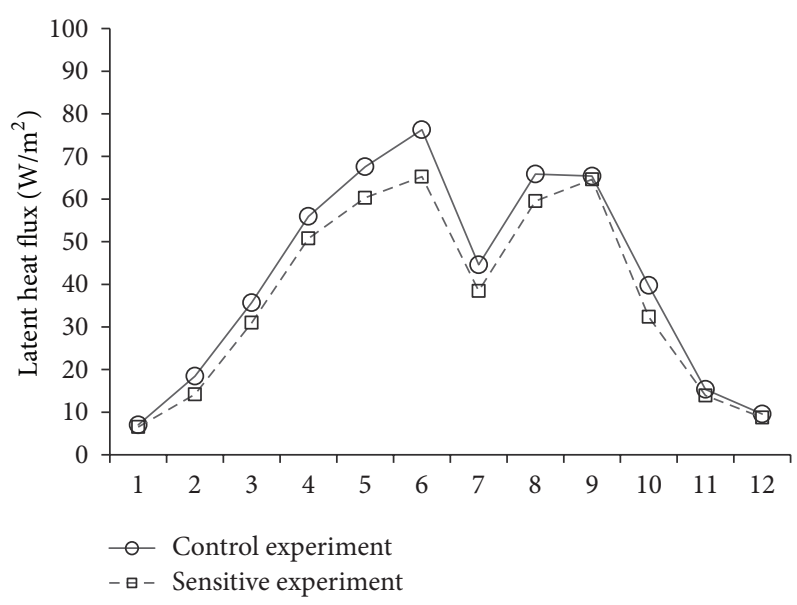

FiguRE 5: Average monthly change of latent heat flux (unit: $\mathrm{W} / \mathrm{m}^{2}$ ) in the overgrazing area of Northwest China from 2010 to 2040.

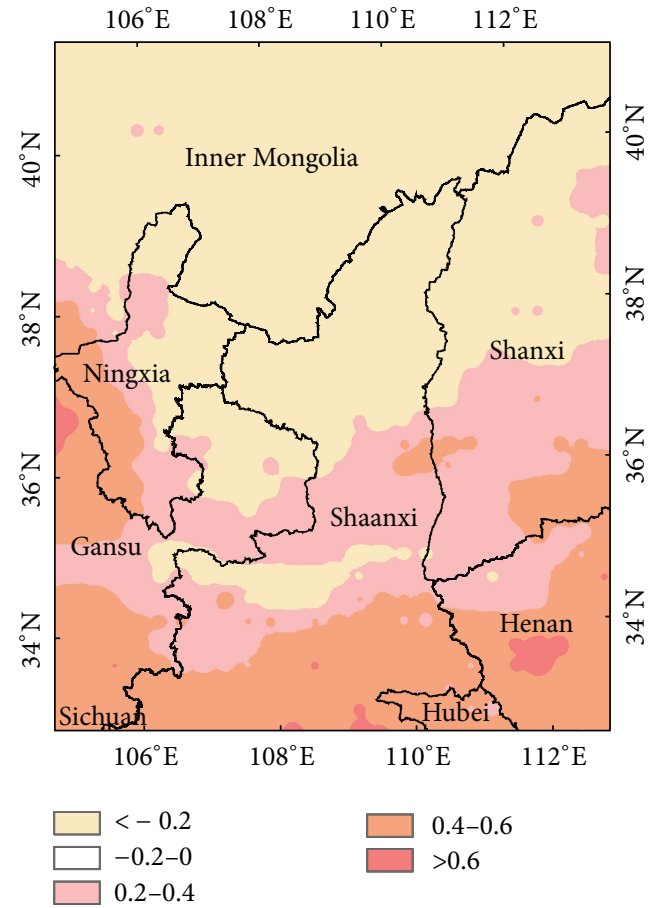

(a)

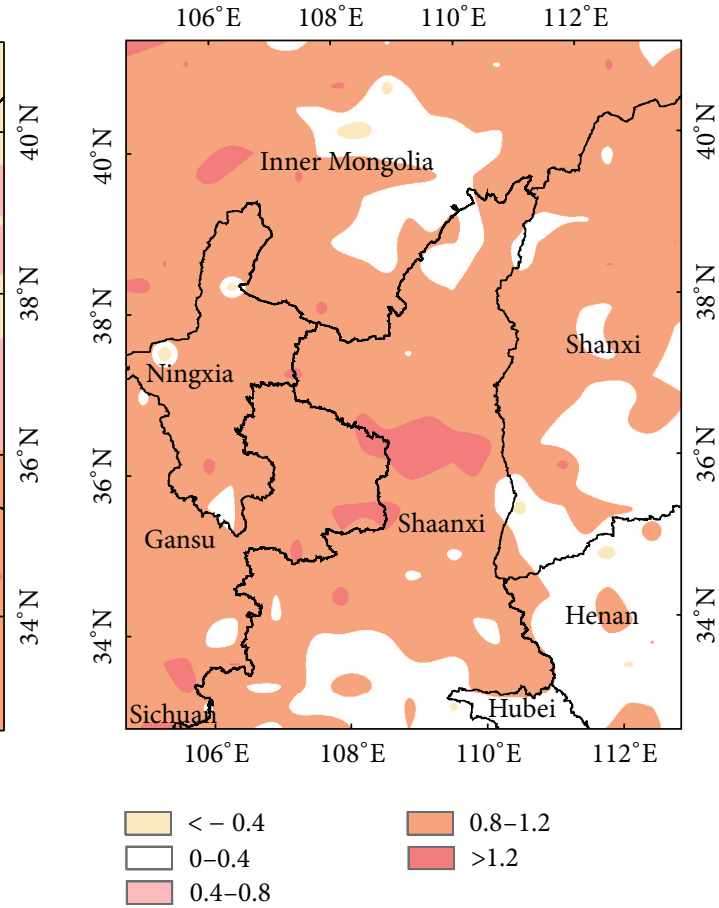

(b)

FiguRE 6: Difference in the annual average temperature (unit: ${ }^{\circ} \mathrm{C}$ ) in the winter (a) and summer (b) from 2010 to 2040 in the overgrazing areas in Northwest China between the sensitivity test and the control test.

croplands, the grassland degradation can mainly result in the decrease of the near-surface temperature of winter in the study area.

The impacts of grassland degradation on the nearsurface temperature are more complicated and widespread in the summer than that in the winter. The grassland degradation can decrease the surface albedo, which will result in the increase of the near-surface temperature in the overgrazing areas of Northwest China, with an increment of about $0.4^{\circ} \mathrm{C}-1.2^{\circ} \mathrm{C}$ (Figure $6(\mathrm{~b})$ ). The temperature rise most obviously in the southwest of Inner Mongolia and middle part of Shaanxi, which are in the overgrazing areas of Northwest China, with the increment of about $1.2^{\circ} \mathrm{C}$.

Although surface temperature of summer decrease in the south part of Inner Mongolia, the south part of Shaanxi Province, and south east of Gansu Province with the drop scale of about $0.4^{\circ} \mathrm{C}$ (Figure 6(b)), which would be caused by the conversion from grassland to croplands since there is obvious difference between the surface albedo of croplands and grassland and the higher evapotranspiration of the croplands, the grassland degradation would mainly lead to the 


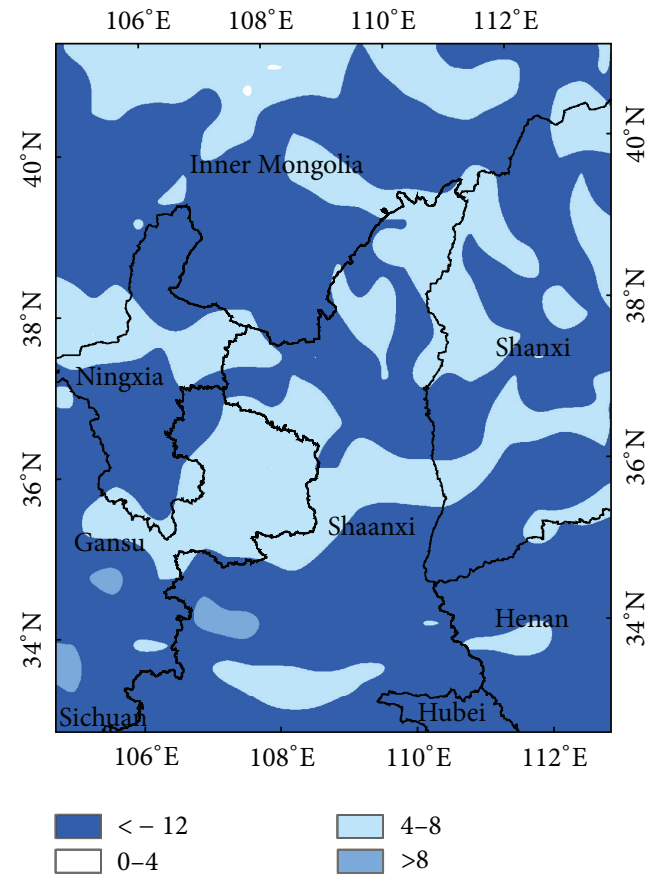

(a)

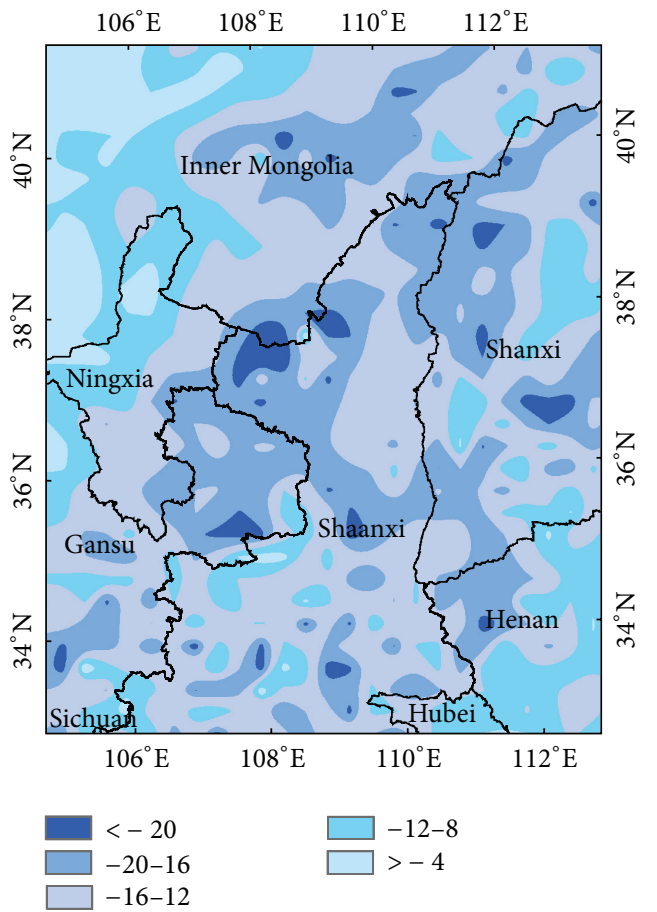

(b)

FIGURE 7: Difference in the annual precipitation (unit: $\mathrm{mm}$ ) in the winter (a) and summer (b) from 2010 to 2040 in overgrazing areas of Northwest China between the sensitivity test and control test.

increase of surface temperature of summer in the overgrazing areas of Northwest China.

3.5. The Effect of Grassland Degradation on Precipitation. The land cover change can influence the precipitation through modifying both the energy balance and water balance [26, 33]. There are very complex impacts of grassland degradation on the precipitation. Due to the complicated interactions between land surface and atmosphere, such as the interactions between land surface albedo, soil moisture, sand temperature, the grassland degradation will increase surface albedo, reduce roughness, and weaken the regulation function of vegetation cover in the water cycle [26].

The simulation result indicates that the grassland degradation can cause the decrease of precipitation in the winter in most part of the overgrazing areas of Northwest China, with a decrement from about $0 \mathrm{~mm}$ to $12 \mathrm{~mm}$ (Figure $7(\mathrm{a})$ ). Particularly, the annual precipitation in the northwest part of Shanxi Province and south part of Inner Mongolia Autonomous Region will decline most obviously due to the serious grassland desertification, with a decrement of about $12 \mathrm{~mm}$. Besides, in the summer, the conversion from grassland to barren land can result in the obvious decrease of precipitation in north and central part of Shanxi Province, north part of Inner Mongolia, and Ningxia Province, with the decrement ranging from about $4 \mathrm{~mm}$ to $20 \mathrm{~mm}$ (Figure 7(b)).

The abovementioned numerical simulation of temperature and precipitation in the next 30 years shows that the grassland degradation in the overgrazing areas of Northwest
China will make the climate change show a dry-warm trend according to the results of both the control test and sensitivity test. The results are consistent with theoretical analysis results that the vegetation degradation will cause the increase of surface albedo, surface sensible heat, and the decrease of latent heat and thereby lead to the decrease of precipitation and increase of temperature [34].

\section{Conclusion and Discussion}

Based on the analysis of grassland change in the future, this study analyzed the impacts of grassland degradation on the regional climate in the overgrazing areas of Northwest China through implementing the numerical simulation with the WRF model. The conclusions of this study are as follows.

The result indicates that the WRF model can well simulate the spatial pattern and change of temperature and precipitation, although the simulated value is a bit lower than the observed value. Besides, the grassland of Northwest China would mainly degrade into croplands, bare land, and urban land over the next 30 years. The most obvious grassland change will occur in the central part of Inner Mongolia Autonomous Region and northwest part of Shaanxi Province.

The simulation result indicates that the grassland degradation will make the climate change in the overgrazing areas of Northwest China show a dry-warm trend in the future 30 years. The grassland degradation will lead to the decrease of latent heat flux through influencing the phase change of water in the atmosphere and the surface-air heat exchange. 
The impacts of grassland degradation on the climate will vary in different seasons. In the summer, the grassland degradation will lead to the increase of surface temperature and decrease of precipitation. While in the winter, it will lead to the decrease of both the precipitation and temperature.

There are generally various impacts of land cover change on the climate change. However, this study has only analyzed the effects of grassland degradation on the temperature and precipitation; therefore, more influencing factors of the climate change should be taken into account in the future research. In addition, there are various factors that influence the regional climate, but in this paper, only the land cover change is used to analyze the impacts of grassland degradation on the regional climate, which leads to some uncertainties of the results. Therefore, more efforts should be made in the future research on the sensitivity test to reduce the uncertainties of the results.

\section{Conflict of Interests}

The authors declare that there is no conflict of interests regarding the publication of this paper.

\section{Acknowledgments}

This study is supported by the China National Natural Science Funds for Distinguished Young Scholar (Grant no. 71225005), National Key Program for Developing Basic Science in China (Grant no. 2012CB955700), and Key Projects in the National Science \& Technology Pillar Program (Grant no. 2013BAC03B03).

\section{References}

[1] X. Deng, C. Zhao, and H. Yan, "Systematic modeling of impacts of land use and land cover changes on regional climate: a review," Advances in Meteorology, vol. 2013, Article ID 317678, 10 pages, 2013.

[2] M. Jin and S. Liang, "An improved land surface emissivity parameter for land surface models using global remote sensing observations," Journal of Climate, vol. 19, no. 12, pp. 2867-2881, 2006.

[3] S. Solomon, D. Qin, M. Manning et al., Contribution of Working Group I to the Fourth Assessment Report of the Intergovernmental Panel on Climate Change, IPCC, Cambridge, UK, 2007.

[4] M. Cai and E. Kalnay, "Impact of land-use change on climate: commentary," Nature, vol. 427, no. 6971, p. 214, 2004.

[5] X. Gao, Y. Luo, W. Lin, Z. Zhao, and F. Giorgi, "Simulation of effects of land use change on climate in China by a regional climate model," Advances in Atmospheric Sciences, vol. 20, no. 4, pp. 583-592, 2003.

[6] J. J. Feddema, K. W. Oleson, G. B. Bonan et al., "Atmospheric science: the importance of land-cover change in simulating future climates," Science, vol. 310, no. 5754, pp. 1674-1678, 2005.

[7] P. Sellers, W. Shut, and J. Dorman, "Calibration of the simplified simple biosphere model (SSiB) for Amazonian pasture and forest sites using LBA data," Acta Amazonian, vol. 35, no. 2, pp. 729-759, 1989.
[8] J. Jin and L. Wen, "Evaluation of snowmelt simulation in the weather research and forecasting model," Journal of Geophysical Research, vol. 117, 2012.

[9] T. Akiyama and K. Kawamura, "Grassland degradation in China Grassland degradation in China: methods of monitoring, management and restoration," Japanese Society of Grassland Science, vol. 53, pp. 1-17, 2007.

[10] J. Jin, S. Lu, S. Li, and N. L. Miller, "Impact of land use change on the local climate over the Tibetan Plateau," Advances in Meteorology, vol. 2010, Article ID 837480, 6 pages, 2010.

[11] J. Fan, H. Zhong, W. Harris et al., "Carbon storage in the grasslands of China based on field measurements of above- and below-ground biomass," Climatic Change, vol. 86, no. 3-4, pp. 375-396, 2008.

[12] F. Barthold, M. Wiesmeier, L. Breuer, H. Frede, J. Wua, and F. Blank, "Land use and climate control the spatial distribution of soil types in the grasslands of Inner Mongolia," Journal of Arid Environments, vol. 88, pp. 194-205, 2012.

[13] G. Xu, M. Kang, and Y. Jiang, "Adaptation to the policyoriented livelihood change in Xilingol grassland, Northern China," Procedia Environmental Sciences, vol. 13, pp. 1668-1683, 2012.

[14] X. Deng, J. Huang, Q. Huang, S. Rozelle, and J. Gibson, "Do roads lead to grassland degradation or restoration? A case study in Inner Mongolia, China," Environment and Development Economics, vol. 16, no. 6, pp. 751-773, 2011.

[15] J. Charney, W. J. Quirk, S.-H. Chow, and J. Kornfield, "A comparative study of the effects of albedo change on drought in semi-arid region," Journal of the Atmospheric Sciences, vol. 34, no. 9, pp. 1366-1385, 1977.

[16] Y. Xue, "The impact of desertification in the Mongolian and the Inner Mongolian grassland on the regional climate," Journal of Climate, vol. 9, no. 9, pp. 2173-2189, 1996.

[17] C. Fu, H. Wei, and W. Zheng, "Sensitivity test of surface coverage types of mainland China in mesoscale model," in Global Change and the Environment in Our Country in the Future, Meteorological Press, Beijing, China, 1996, (Chinese).

[18] J. Zhang, W. Dong, and C. Fu, "Impact of land surface degradation in northern China and southern Mongolia on regional climate," Chinese Science Bulletin, vol. 50, no. 1, pp. 75-81, 2005.

[19] Y. Liu and S. Lv, "Numerical simulation of the impact of the grassland desertification on local climate in the Source Region of Three Rivers," Journal of Arid Land Resources and Environment, vol. 6, no. 21, pp. 131-135, 2007 (Chinese).

[20] Y. Xue and J. Shukla, "The influence of land surface properties on Sahel climate. Part I: desertification," Journal of Climate, vol. 6, no. 12, pp. 2232-2245, 1993.

[21] B. Fu, L. Wei, and W. Zhen, Sensitivity Test of Mesoscale Model to Surface Cover Type of the Chinese Mainland, China Meteorological Press, Beijing, China, 1996.

[22] H. Mao, X. Yan, Z. Xiong, and H. Tian, "Modeled impact of irrigation on regional climate in India," Acta Ecologica Sinica, vol. 31, no. 4, pp. 1038-1045, 2011 (Chinese).

[23] J. Jin, M. L. Miller, and N. Schlegel, "Sensitivity study of four land surface schemes in the WRF model," Advances in Meteorology, vol. 2010, Article ID 167436, 11 pages, 2010.

[24] M. Wang, X. Zhang, and X. Yan, "Modeling the climatic effects of urbanization in the Beijing-Tianjin-Hebei metropolitan area," Theoretical and Applied Climatology, p. 9, 2012 (Chinese).

[25] P. Caldwell, H.-N. S. Chin, D. C. Bader, and G. Bala, "Evaluation of a WRF dynamical downscaling simulation over California," Climatic Change, vol. 95, no. 3-4, pp. 499-521, 2009. 
[26] C. V. Srinivas, D. Hariprasad, D. V. Bhaskar Rao, Y. Anjaneyulu, R. Baskaran, and B. Venkatraman, "Simulation of the Indian summer monsoon regional climate using advanced research WRF model," International Journal of Climatology, vol. 33, no. 5, pp. 1195-1210, 2013.

[27] K. Taylor, R. Stouffer, and G. Meehl, "An overview of CMIP5 and the experiment design," Bulletin of the American Meteorological Society, vol. 93, no. 4, pp. 485-498, 2012.

[28] M. Mohan and S. Bhati, "Analysis of WRF model performance over subtropical region of Delhi, India," Advances in Meteorology, vol. 2011, Article ID 621235, 13 pages, 2011.

[29] S.-Y. Hong and H.-L. Pan, "Nonlocal boundary layer vertical diffusion in a medium-range forecast model," Monthly Weather Review, vol. 124, no. 10, pp. 2322-2339, 1996.

[30] G. A. Grell and D. Dévényi, "A generalized approach to parameterizing convection combining ensemble and data assimilation techniques," Geophysical Research Letters, vol. 29, no. 14, pp. 38$1,2002$.

[31] F. Wu, X. Deng, F. Yin, and Y. Yuan, "Projected changes of grassland productivity along the representative concentration pathways during 2010-2050 in China," Advances in Meteorology, vol. 2013, Article ID 812723, 9 pages, 2013.

[32] J. L. Schedlbauer, S. F. Oberbauer, G. Starr, and K. L. Jimenez, "Controls on sensible heat and latent energy fluxes from a shorthydroperiod Florida Everglades marsh," Journal of Hydrology, vol. 411, no. 3-4, pp. 331-341, 2011.

[33] L. Lian and J. Shu, "Simulation of effects of grassland degradation on regional climate over sanjiangyuan region in QinghaiTibet plateau," Acta Meteorologica Sinica, vol. 23, no. 3, pp. 350$362,2009$.

[34] M. V. K. Sivakumar, "Interactions between climate and desertification," Agricultural and Forest Meteorology, vol. 142, no. 2-4, pp. 143-155, 2007. 

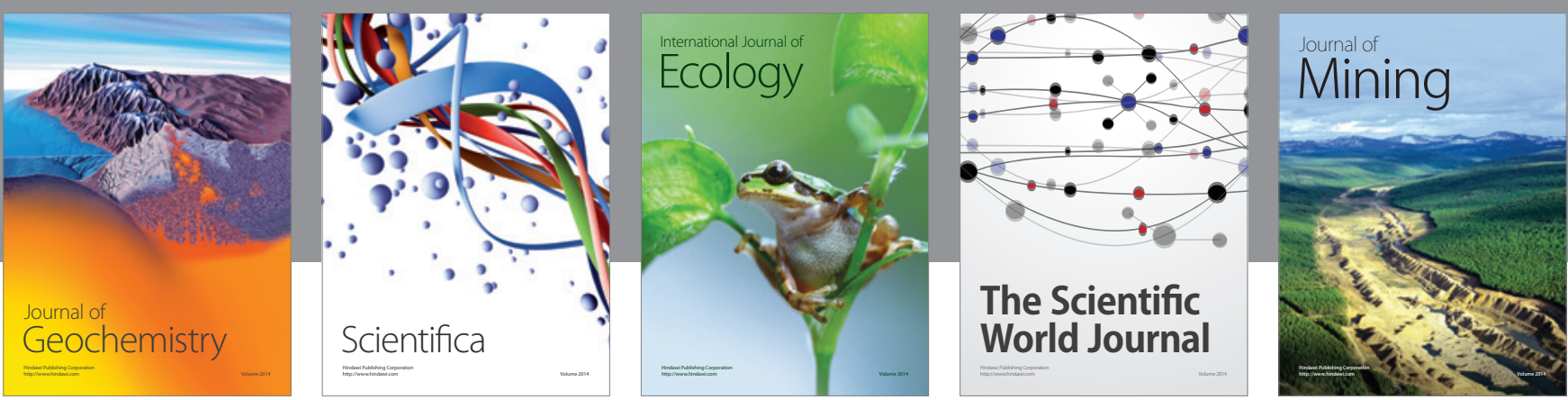

The Scientific World Journal
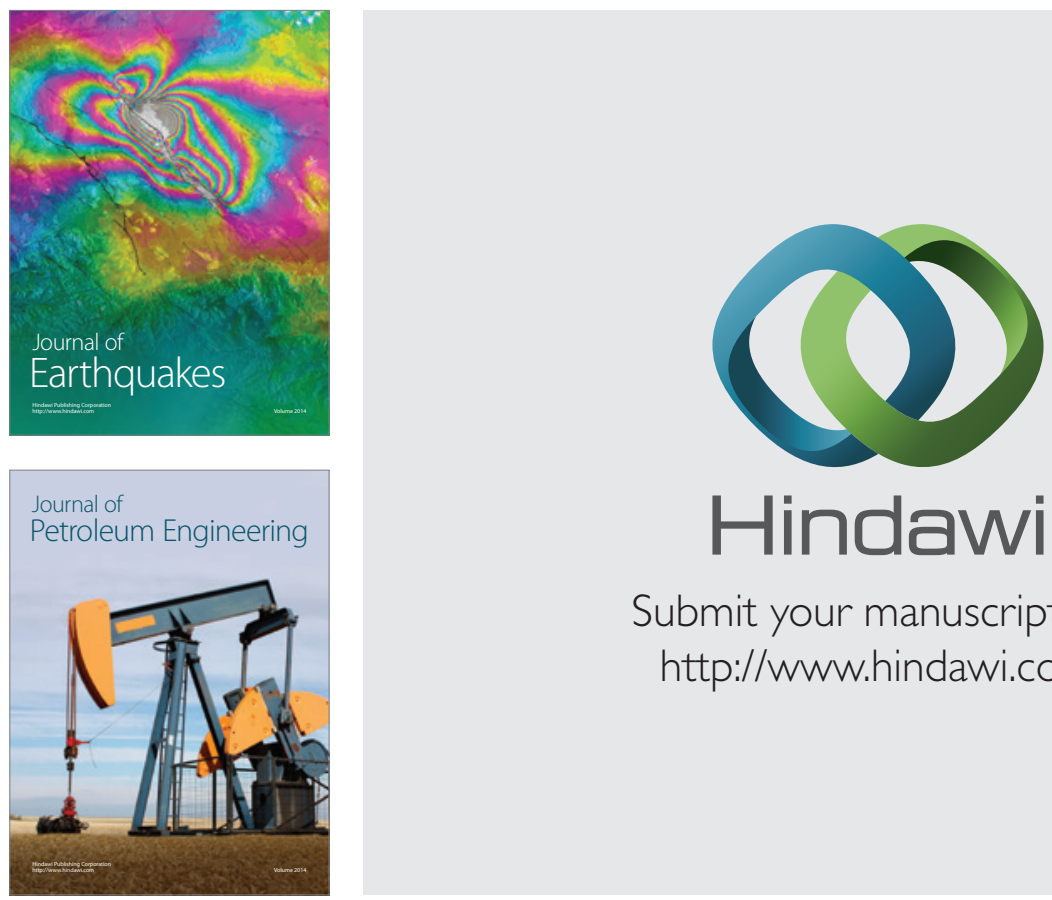

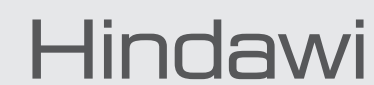

Submit your manuscripts at

http://www.hindawi.com
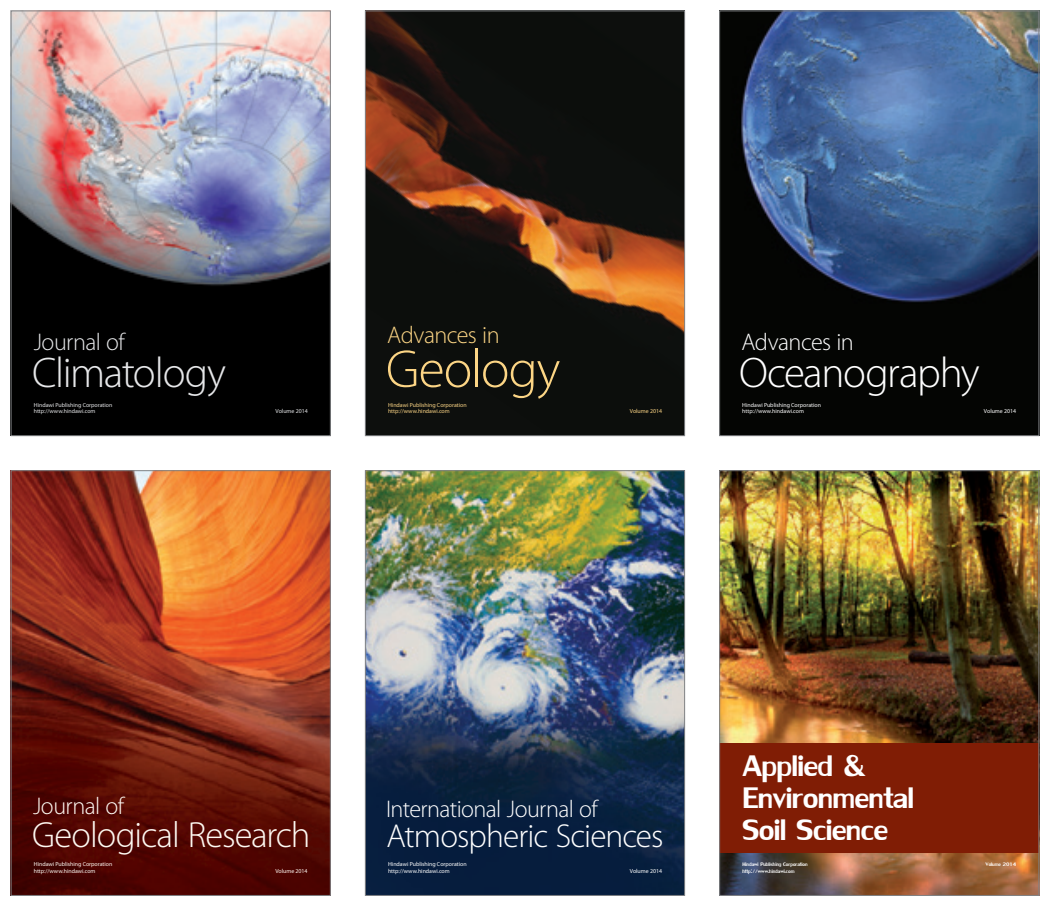
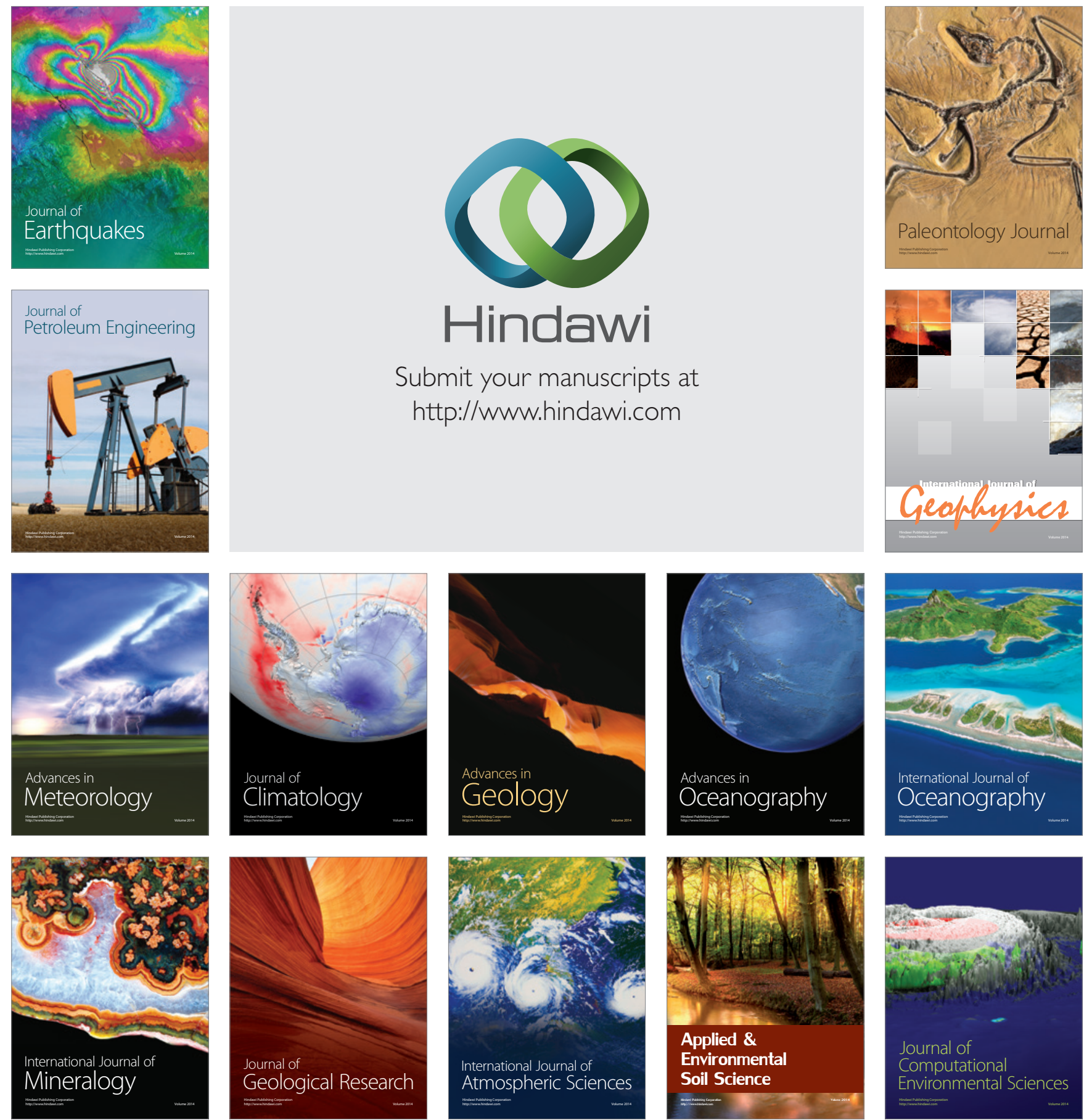